\title{
B-LYNCH UTERINE COMPRESSION SUTURES IN PPH-AN EXPERIENCE AT TERTIARY CARE CENTRE
}

\author{
Polumuru Usha Devi' 1 Balla Sudha Rani², Prasad Usha ${ }^{3}$
}

${ }_{1}^{1}$ Assistant Professor, Department of Obstetrics and Gynaecology, Andhra Medical College, Visakhapatnam, Andhra Pradesh. 2 Professor and HOD, Department of Obstetrics and Gynaecology, GVP Institute of Health Care and Medical Technology, Madhurwada, Visakhapatnam, Andhra Pradesh.

${ }^{3}$ Assistant Professor, Department of Obstetrics and Gynaecology, Andhra Medical College, Visakhapatnam, Andhra Pradesh.

\section{ABSTRACT}

\section{BACKGROUND}

The commonest cause of postpartum hemorrhage is uterine atony. It is a serious obstetrical problem and contributes to $25-43 \%$ of all maternal deaths in the developing countries. This suture technique was described by Christopher B-Lynch in 1997 that envelope and compresses the uterus to control life-threatening postpartum hemorrhage.

\section{AIM OF THE STUDY}

To study the effectiveness of B-Lynch uterine compression sutures in the control of PPH.

\section{MATERIAL AND METHODS}

A prospective 2-year observational study, a total of 100 cases of B-Lynch was performed and results analyzed.

\section{RESULTS}

The study includes 100 B-Lynch applications in 12,950 deliveries. Multiparous women were at a greater risk [56\%]. Obstetric complications associated with PPH were PIH [29\%], APH [Placenta praevia 14\% and abruption 10\%], Twins [17\%], anaemia [11\%], polyhydramnios [4\%]. Emergency LSCS was the most common procedure associated with atonic PPH [68\%] followed by Elective LSCS [28\%]. In this study, additional procedures required were uterine and ovarian artery ligation in 24 cases [24\%] and hysterectomy in 2 cases [2\%].

\section{CONCLUSION}

B-Lynch suture is a valuable addition to surgical management of PPH because of its ease of application, lifesaving potential and its capacity to preserve the uterus. Hysterectomy is associated with morbidity in a young woman in addition to loss of fertility, which can be avoided by application of B-Lynch suture.

\section{KEYWORDS}

B-Lynch Sutures, Maternal Deaths, Obstetric Hysterectomy, PPH B-Lynch Uterine Compression Sutures in PPH-An experience at Tertiary Care Centre.

HOW TO CITE THIS ARTICLE: Devi PU, Rani BS, Usha P. B-Lynch uterine compression sutures in PPH-an experience at tertiary care centre. J. Evolution Med. Dent. Sci. 2016; 5(12):500-502, DOI: 10.14260/jemds/2016/114

\section{INTRODUCTION}

PPH is the most common cause of maternal deaths and accounts for one-quarter of deaths worldwide. About 1,50,000 women bled to death during or immediately after labor worldwide.[1] In developing countries, PPH contributes to $17-$ $40 \%$ of maternal mortality and $40 \%$ maternal morbidity.[2] Atonicity of the uterus is the most common cause of postpartum hemorrhage. It accounts for $75-90 \%$ of $\mathrm{PPH}$. Postpartum haemorrhage is a potentially life-threatening complication associated with fetal delivery.[3] It may occur after vaginal delivery (4\%) or caesarean section $(6 \%) .[4,5]$

\section{MATERIAL AND METHODS}

A prospective 2-year observational study conducted at a

Financial or Other, Competing Interest: None.

Submission 26-12-2015, Peer Review 23-01-2016,

Acceptance 27-01-2016, Published 09-02-2016.

Corresponding Author:

Dr. Prasad Usha,

QNo 49-3-3, Lalithanagar,

Visakhapatnam-530016,

Andhra Pradesh.

E-mail: ushaprasad411@gmail.com

DOI: 10.14260/jemds/2016/114
Tertiary Care Centre, where around 6000 to 7000 deliveries occur annually. A total of 100 cases of B-Lynch were performed during this period. In all cases, the procedure was performed after failure of medical treatment. The exclusion criteria were,

1. Genital tract lacerations.

2. Blood coagulation disorders.

3. Retained placenta.

\section{PROCEDURE}

Women were positioned in frog leg supine position, which is important for assessing vaginal bleeding intraoperatively and determining the success of bimanual compression and the BLynch suture. For this procedure chromic catgut No. 2 on round bodied needle was used. Modified B-Lynch suture was applied where we had already closed the LSCS incision on the uterus and then because of uterine atony decision was taken to apply B-Lynch suture. LSCS sutures were not reopened. This was useful also when we were applying B-Lynch to control postpartum hemorrhage following vaginal delivery, thus avoiding a uterine incision. Additional procedures along with B-Lynch like uterine and ovarian artery ligation and if 
necessary hysterectomy when B-Lynch compression suture failed to control bleeding were recorded.

Vital data before the procedure and after the procedure were checked and recorded. Blood loss measured before and after the procedure.

\section{RESULTS}

The study includes 100 B-Lynch applications in 12,950 deliveries. The age group with maximum incidence was between 21-25 years [61\%]. Multiparous women were at a greater risk [56\%] [Table 1]. Obstetric complications associated with PPH were PIH [29\%], APH [Placenta praevia $14 \%$ and abruption 10\%], Twins [17\%], anaemia [11\%], polyhydramnios [4\%]. In 15 cases [15\%], there were no known risk factors for PPH [Table 2]. Emergency LSCS was the most common procedure associated with atonic PPH [68\%] followed by Elective LSCS [28\%]. Atonic PPH was seen in 4 cases [4\%] of vaginal deliveries [Table 3]. A total of 64 cases required blood transfusion of which 8 cases [8\%] required 3 units and 6 [6\%] required 4 units [Table 4]. In this study, additional procedures required were uterine and ovarian artery ligation in 24 cases [24\%] and hysterectomy in 2 cases [2\%]. Additional procedures were mostly required in cases of placenta praevia [Table 5].

\begin{tabular}{|c|c|}
\hline Age & Number of Cases [Percentage] \\
$<20$ years & $33[33 \%]$ \\
$20-25$ years & $61[61 \%]$ \\
$26-30$ years & $6[6 \%]$ \\
\hline Parity & \\
Primi & $44[44 \%]$ \\
Multi & $56[56 \%]$ \\
\hline \multicolumn{2}{|c|}{ Table 1: Demographic Factors } \\
\hline
\end{tabular}

\begin{tabular}{|c|c|}
\hline $\begin{array}{c}\text { Obstetric } \\
\text { Complications }\end{array}$ & Number of Cases [Percentage] \\
\hline PIH & $29[29 \%]$ \\
\hline Placenta praevia & $14[14 \%]$ \\
\hline Abruption & $10[10 \%]$ \\
\hline Polyhydramnios & $4[4 \%]$ \\
\hline Anaemia & $11[11 \%]$ \\
\hline Twins & $17[17 \%]$ \\
\hline Total & $\mathbf{8 5}$ \\
\hline \multicolumn{2}{|c|}{ Table 2: Risk Factors } \\
\hline
\end{tabular}

\begin{tabular}{|c|c|}
\hline Mode of Delivery & Number of Cases [Percentage] \\
\hline Vaginal & $4[4 \%]$ \\
\hline Emergency LSCS & $68[68 \%]$ \\
\hline Elective LSCS & $28[28 \%]$ \\
\hline Total & $\mathbf{1 0 0}$ \\
\hline \multicolumn{2}{|c|}{ Table 3: Mode of Delivery } \\
\hline
\end{tabular}

\begin{tabular}{|c|c|}
\hline Units of Blood & Number of Cases [Percentage] \\
\hline 1 & $36[36 \%]$ \\
\hline 2 & $14[14 \%]$ \\
\hline 3 & $6[6 \%]$ \\
\hline 4 & $8[8 \%]$ \\
\hline Total & $\mathbf{6 4 [ 6 4 \% ]}$ \\
\hline \multicolumn{2}{|c|}{ Table 4: Need for Blood Transfusion } \\
\hline
\end{tabular}

\begin{tabular}{|c|c|}
\hline Type of Intervention & $\begin{array}{c}\text { Number of Cases } \\
\text { [Percentage] }\end{array}$ \\
\hline B-Lynch/Modified B-Lynch & $74[74 \%]$ \\
\hline $\begin{array}{l}\text { Uterine A/Ovarian A ligation } \\
\text { plus } \\
\text { B-Lynch/Modified B-Lynch }\end{array}$ & $24[24 \%]$ \\
\hline Hysterectomy & $2[2 \%]$ \\
\hline Total & 100 \\
\hline \multicolumn{2}{|c|}{ Table 5: Type of Intervention } \\
\hline
\end{tabular}

\section{DISCUSSION}

We report our experience with uterine compression sutures that were developed as uterine-salvaging procedures for the treatment of PPH. In our study, indication for application of BLynch suture was uterine atony in $86 \%$ of cases and placental causes in $14 \%$ of cases. In this study, 74 cases achieved hemostasis with B-Lynch alone and in 24 cases uterine and ovarian artery ligation was performed along with B-Lynch suture. B-Lynch failed to control bleeding and hysterectomy was performed in 2 cases. A study by Wohlmuth et al.[6] described 22 cases: 11 cases obtained hemostasis with the BLynch suture alone and six cases with the suture and uterine and/or ovarian artery ligation. They had a $77.3 \%$ success rate, similar to the 28 cases reported by Baskett.[7] who had an $82.1 \%$ success rate. In our study, success rate of avoiding hysterectomy was $98 \%$.

The success rate of uterine compression sutures has been reported to be 77 to $82 \%$ in several case series. Price and B-Lynch.[8] presented a detailed review of 15 published reports, which included 46 cases with two failures. Faruqi et al.[9] performed B-Lynch suture on 45 women to control PPH. They applied this suturing technique successfully in $44 / 45$ patients with failure rate of $2.22 \%$. Choudry.[10] Performed BLynch suture on 17 patients with refractory PPH of whom 12 were applied at cesarean section and five was a sequel to vaginal delivery. The procedure was successful in 14 patients. Failure of B-Lynch was more with placenta previa, previous CS and DIC. These conclusions were similar to our study.

\section{CONCLUSION}

B-Lynch suture is a valuable addition to surgical management of PPH because of its ease of application, life-saving potential and its capacity to preserve the uterus. Hysterectomy is associated with morbidity in a young woman in addition to loss of fertility, which can be avoided by application of B-Lynch suture. It is less effective in cases of PPH due to placenta praevia. Long-term followup is required in these patients to assess effect on fertility and menstrual function.

\section{REFERENCES}

1. World Health Organization. Preventing maternal deaths. Geneva: WHO, 1989;107-36.

2. World Health Organization. Maternal mortality, a global feedback. Geneva; WHO, 1991, 3-16.

3. Lewis G. The Confidential Enquiry into Maternal and Child Health (CEMACH), Eds., Saving Mothers' Lives: Reviewing Maternal Deaths to Make Motherhood Safer2003-2005. The seventh report on the confidential enquiries into maternal deaths in the United Kingdom. The Confidential Enquiry into Maternal and Child Health (CEMACH), London, UK, 2007. 
4. Combs CA, Murphy EL and Laros RK, Jr. "Factors associated with postpartum hemorrhage with vaginal birth." Obstetrics and Gynecology, vol. 77, no. 1, pp. 69-76, 1991.

5. Prasertcharoensuk W, Swadpanich U and Lumbiganon P. "Accuracy of the blood loss estimation in the third stage of labor." International Journal of Gynaecology and Obstetrics, vol. 71, no. 1, pp. 69-70, 2000.

6. Wohlmuth CT, Gumbs J, Quebral-Ivie J. B-Lynch suture: a case series. Int J Fertil Womens Med 2005;50:164-73.

7. Baskett TF. Uterine compression sutures for postpartum hemorrhage: efficacy, morbidity and subsequent pregnancy. Obstet Gynecol 2007;110:68-71.
8. Price N, B-Lynch C. Technical description of the B-Lynch brace suture for treatment of massive postpartum hemorrhage and review of published cases. Int J Fertil Womens Med 2005;50:148-163.

9. Faruqi NJ, Javed L, Yousaf F, et al. B-Lynch suture for the management of postpartum hemorrhage - local experience.

Ann King Edward Med Coll 2004;10:370-373.

10. Choudry A, Mirza Z. The B-Lynch suture technique for the control of massive PPH because of uterine atony. Ann Park Inst Med Sci 2005;1:4-6. 